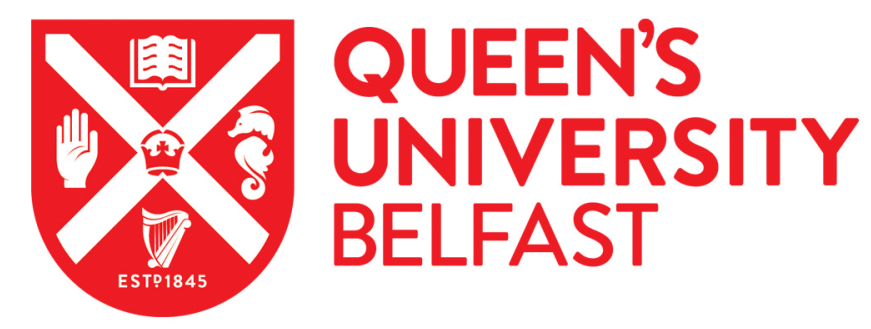

\title{
Learning about probability from text and tables: Do color coding and labeling through an interactive-user interface help?
}

Clinton, V., Morsanyi, K., Alibali, M. W., \& Nathan, M. J. (2016). Learning about probability from text and tables: Do color coding and labeling through an interactive-user interface help? Applied Cognitive Psychology. https://doi.org/10.1002/acp.3223

Published in:

Applied Cognitive Psychology

Document Version:

Peer reviewed version

Queen's University Belfast - Research Portal:

Link to publication record in Queen's University Belfast Research Portal

\author{
Publisher rights \\ (C) 2016 John Wiley \& Sons, Ltd \\ This is the peer reviewed version of the following article: Clinton, V., Morsanyi, K., Alibali, M. W., and Nathan, M. J. (2016) Learning about \\ Probability from Text and Tables: Do Color Coding and Labeling through an Interactive-user Interface Help?. Appl. Cognit. Psychol., doi: \\ 10.1002/acp.3223, which has been published in final form at http://dx.doi.org/10.1002/acp.3223. This article may be used for non-commercial \\ purposes in accordance with Wiley Terms and Conditions for Self-Archiving.
}

\section{General rights}

Copyright for the publications made accessible via the Queen's University Belfast Research Portal is retained by the author(s) and / or other copyright owners and it is a condition of accessing these publications that users recognise and abide by the legal requirements associated with these rights.

Take down policy

The Research Portal is Queen's institutional repository that provides access to Queen's research output. Every effort has been made to ensure that content in the Research Portal does not infringe any person's rights, or applicable UK laws. If you discover content in the Research Portal that you believe breaches copyright or violates any law, please contact openaccess@qub.ac.uk. 
Running Head: Color Coding and Labeling

Learning about Probability from Text and Tables: Do Color Coding and Labeling through an Interactive-User Interface Help?

\author{
Virginia Clinton \\ University of North Dakota \\ Kinga Morsanyi \\ Queen's University Belfast \\ Martha W. Alibali \& Mitchell J. Nathan \\ University of Wisconsin-Madiso
}

Author Note

Virginia Clinton is an Instructor at the University of North Dakota. Correspondence should be addressed to Virginia Clinton, 319 Harvard St., Grand Forks, ND 58202 or virginia.clinton@und.edu.

Please cite as the following:

Clinton, V., Morsanyi, K., Alibali, M.W., \& Nathan, M.J. (in-press). Learning about probability from text and tables: Do color coding and labeling through an interactive-user interface help? Applied Cognitive Psychology. doi: 10.1002/acp.3223 


\begin{abstract}
Learning from visual representations is enhanced when learners appropriately integrate corresponding visual and verbal information. This study examined the effects of two methods of promoting integration, color coding and labeling, on learning about probabilistic reasoning from a table and text. Undergraduate students $(N=98)$ were randomly assigned to learn about probabilistic reasoning from one of 4 computer-based lessons generated from a 2 (color coding/no color coding) by 2 (labeling/no labeling) between-subjects design. Learners added the labels or color coding at their own pace by clicking buttons in a computer-based lesson. Participants' eye movements were recorded while viewing the lesson. Labeling was beneficial for learning, but color coding was not. In addition, labeling, but not color coding, increased attention to important information in the table and time with the lesson. Both labeling and color coding increased looks between the text and corresponding information in the table. The findings provide support for the multimedia principle (Mayer, 2009), and they suggest that providing labeling enhances learning about probabilistic reasoning from text and tables. Keywords: probabilistic reasoning; instructional design principles; eyetracking
\end{abstract}




\section{Learning about Probability from Text and Tables: \\ Do Color Coding and Labeling Help?}

Many people struggle with probabilistic reasoning, especially when calculating posterior probability (Evans, Handley, Perham, Over \& Thompson, 2000; Kahneman \& Tversky, 1973; Stanovich \& West, 1998). Posterior probability judgments require the evaluation of a hypothesis after being presented with relevant data. Such calculations can be used, for example, to judge the probability that a person who tested positive for a disease, actually has the disease. In order to make a correct judgment about this problem, people have to consider three pieces of information: (a) the true positive rate: the probability of the test giving a positive result when the person actually has the disease; (b) the false positive rate: the probability of the test giving a positive result when the person does not have the disease; and (c) the base rate/prevalence: the probability that a randomly chosen person from the population has the disease. People often fail to integrate these three pieces of information appropriately, and, thus, they often generate incorrect

responses. Because of the complexity of probabilistic reasoning, teaching probabilistic reasoning is also quite challenging (Garfield \& Ben-Zvi, 2008). Given the ubiquity of test results in modern society, it is important to understand this type of probabilistic reasoning (Hoffrage, Kurzenhäuser, \& Gigerenzer, 2005; Kurzenhäuser \& Hertwig, 2006) and to develop effective ways to instruct people about it.

Visual representations, such as tables and diagrams, have been found to be beneficial in instruction on calculating posterior probability (Kurzenhäuser \& Hoffrage, 2002; Sedlmeier \& Gigerenzer, 2001). However, learners do not always use visual representations effectively, and they often fail to adequately integrate visual information with corresponding verbal information (Seufert, 2003). Thus, learners may benefit from instructional design techniques that support 
their integrating corresponding ideas in visual and verbal representations (de Koning, Tabbers, Rikers, \& Paas, 2009). The purpose of this study is to test the effects of two such instructional design techniques, color coding and labeling, on learning from a computer-based lesson about posterior probability.

\section{Theoretical Background}

According to the multimedia principle (Mayer, 2002, 2009), visual representations enhance learning because of the connections they afford with verbal information in text or speech (Mayer, 2002, 2005, 2009). When using materials with both verbal and visual information, learners create a verbal mental model based on information presented in text or speech, as well as a visual mental model based on information presented in the visuals (Mayer, 2009). When learners select and integrate corresponding information in the verbal and visual representations, connections are made between the two mental models (Mayer, 1999). Thus, in the case of a posterior probability lesson presented with text and visuals, learners can integrate verbal descriptions of how posterior probability works with a relevant visual representation. For example, a learner could select the verbal description of a true positive as well as the visual portraying a true positive in a hypothetical data set. Then, the learner could integrate the information regarding true positives in the two representations. This integration of verbal and visual information may increase comprehension of the material, which in turn may increase learning (Schnotz, 2002). However, in order for this integration to occur, it is important that 1 
earners properly attend to and connect the corresponding information in verbal and visual representations (de Koning et al., 2009; Mayer, 2003).

Integrating corresponding information in different representations can be especially challenging in written lessons because of the split attention effect, in which a learner's visual attention is divided between the two representations (Chandler \& Sweller, 1991, 1992). Simply put, learners cannot look at both the visual representation and the text at the same time, making integrating different sources of information cognitively demanding. In an oral lesson, learners can listen to the verbal information and view the visual representation simultaneously (Mousavi, Low \& Sweller, 1995; Moreno \& Mayer, 1999). Furthermore, instructors can guide connections between corresponding verbal and visual information through gesture (Alibali et al., 2014; Nathan \& Alibali, 2011). However, when learners independently read a written lesson, they may have difficulty connecting the information in text with the information in the visual representation because of the split attention effect (Low \& Sweller, 2005). Learners must maintain information from one representation in working memory while searching for corresponding information in the other representation (Kalyuga, Chandler, \& Sweller, 1999). For this reason, when learners need attend to both a visual representation and the corresponding written text, they may benefit from support for making connections between the visual representation and the text.

Lessons with text and visual information may be more effective if they include supports for making connections. Two such techniques that have been found to be effective in past research based on science lessons are color coding and labeling (Florax \& Ploetzner, 2010; Ozcelik, Karakus, Kursun, \& Cagiltay, 2009). Color coding and labeling can assist learners both 
in selecting important information and in integrating corresponding information in visual representations and text.

Color coding involves presenting corresponding information in the same color, but one that contrasts with the surrounding information. Previous research findings have indicated that color coding corresponding information in text and visual representations increased learning (Kalyuga et al., 1999; Keller, Gerjets, Scheiter, \& Garsoffky, 2006). This is likely because color provides a visual contrast that may signal the learner that information is important or related, thereby assisting in selecting and attending to important information (Schnotz \& Lowe, 2008; Tabbers, Martens, \& van Merriënboer, 2004). Selecting and attending to important components of visual representations is critical for learning, because learners must first identify and process relevant information in the visual representations before they can integrate the information in the visual representation with the text (Mayer, 1996). Moreover, the use of shared color can guide connections between verbal and visual representations (Ozcelik et al., 2009; Ozcelik, Arslan-Ari, Cagiltay, 2010). This is because learners can use the shared color to quickly identify information that should be connected (Cook, 2006; Patrick, Carter, \& Wiebe, 2005). Learners can then focus more cognitive resources on understanding the material, which can lead to better learning (Mayer, 2009).

Labeling, which involves adding text to visual representations, can also help learners select and integrate information in different representations. Like color coding, labels can signal the learner that information is important or relevant. Through this signaling, learners can use labels to help them select and attend to important components of visual representations (Florax \& Ploetzner, 2010; Johnson \& Mayer, 2012). In addition, because a label is comprised of text, labeling allows for text to be in close proximity to corresponding visual information, thereby 
making verbal and visual representations more spatially contiguous, which cues the learner that the information from the two representations should be connected (Holsanova, Holmberg, \& Holmquist, 2009). Furthermore, the spatial contiguity of corresponding verbal and visual information provided by labels may assist learners in connecting the words in the label with those same words in the main body of text. This may ease visual searches for information (Johnson \& Mayer, 2012). In these ways, labeling can guide the integration of corresponding information in the text and visual representations (Mason, Pluchino, \& Tornatora, 2013b). As with color coding, labeling decreases the cognitive resources needed for selecting important information and making connections, which increases the availability of cognitive resources for learning.

Instructional design techniques such as color coding and labeling have typically been examined in isolation (Florax \& Ploetzner, 2010; Mason et al., 2013b; Ozcelik et al., 2009, 2010). That is, learning from a lesson with one of these techniques has usually been compared to learning from a lesson without that specific technique (however, see Jamet, Gavota, \& Quaireau, 2008, for an exception). It is possible that using two instructional design techniques simultaneously may be particularly beneficial because each adds distinct benefits; that is, color coding and labeling signal important information and guide integration in different ways. Indeed, the use of two instructional design techniques (e.g., color coding and presenting information step by step) in oral presentations was found to be particularly helpful for retention of lesson information (Jamet et al., 2008). However, no research to date has addressed the possibility that a combination of color coding and labeling could lead to greater learning from written lessons than either technique on its own. It is possible that combining color coding and labeling could be especially beneficial because leaners would have two techniques designed to enhance the 
selection of important information and integration of text and visuals, and these effects could be additive. Conversely, it is possible that color coding and labeling serve such similar functions that combining them may not yield any additional benefit. Without testing the combination, it is uncertain whether optimal design of instructional materials should involve labels only, color coding only, or the combination of both.

Color coding and labeling may be particularly effective when implemented in computerbased lessons because, unlike traditional lessons on paper, computer-based lessons can have interfaces that permit (or require) learners to add the color coding and labeling themselves (see Najjar, 1998). Labeling and color coding can be added by having learners click on buttons to make labels and color codes appear. This approach may maximize the benefits of labeling and color coding because it affords the opportunity to show a single label or color code at a time. With only one cue at a time, learners can better focus their attention on the color coded and/or labeled areas (O'Byrne, Patry, \& Carnegie, 2008). Indeed, the benefits of labeling appear to be enhanced if learners interacted with a computer interface to reveal each of the labels (Evans \& Gibbons, 2007). Furthermore, this design permits learners to view the labels and color codes at their own pace, and to review them multiple times if necessary, which also may promote learning (Boucheix \& Guignard, 2005; Mayer \& Chandler, 2001).

\section{Need for Cognition}

Past research findings indicate that performance on probabilistic reasoning tasks is associated with a thinking disposition known as need for cognition. Need for cognition is the tendency for an individual to engage in and enjoy effortful cognitive activities (Cacioppo \& Petty, 1982). Individuals with high levels of need for cognition are more likely to process and systematize information, sorting out the irrelevant from the important, than individuals with low 
levels of need for cognition (Cacioppo \& Petty, 1984; for a review on need for cognition, see Cacioppo, Petty, Feinstein, \& Jarvis, 1996). Additionally, individuals with high levels of need for cognition engage in cognitively challenging activities without external motivation (Heijltjes, van Gog, Leppink, \& Paas, 2014), whereas individuals with low levels of need for cognition prefer to engage in effortful cognitive tasks only when they have a good reason to do so (Haugtvedt, Petty, \& Cacioppo, 1992). Because need for cognition is associated with enjoyment of complex and effortful cognitive tasks, it has been found to be positively related to logical reasoning (e.g., Smith \& Levin, 1996; Jarvis \& Petty, 1996). Moreover, in educational contexts, need for cognition is positively associated with academic achievement (see Sadowski \& Gulgoz, 1992).

Researchers have shown that need for cognition is positively related to performance on probabilistic reasoning tasks (Kokis et al., 2002; West, Toplak \& Stanovich, 2008). This is likely because need for cognition is positively associated with an inclination to think deeply about problems (Morsanyi, Primi, Chiesi, \& Handley, 2009). For these reasons, we also considered individual differences in need for cognition in examining the effectiveness of lessons on probabilistic reasoning.

\section{The Current Study}

The purpose of the current study is to investigate the effects of color coding and labeling, previously found to be effective in learning from multiple representations in science lessons, on learning about posterior probability from a table and text. Posterior probability was a suitable topic for investigating this issue because it is frequently challenging for undergraduate students to integrate all of the relevant information (Kahnman \& Tversky, 1973; Morsanyi, Handley \& Serpell, 2013). Therefore, support from color coding and labeling may be particularly helpful. 
Tables were chosen as a visual because they are commonly used when teaching posterior probability (Steckelberg, Balgenorth, Berger, Muhlhaüser, 2004). As our primary research question, we asked whether color coding and labeling would promote learning about posterior probability. Based on previous findings (e.g., Boucheix \& Lowe, 2010; Catrambone, 1994, 1996; de Koning et al., 2010; Florax \& Ploetzner, 2010; Johnson \& Mayer, 2012; Mason et al., 2013b; Ozcelik et al, 2009, 2010), we expected that both color coding and labeling would increase learning about posterior probability. However, we were uncertain as to which would be more effective given that both have been shown to be beneficial and they had not been previously compared to each other. It is also possible that a combination of color coding and labeling would yield the greatest increases in learning. A combination of color coding and labeling would provide two forms of guidance while learning, which could be beneficial for a complex topic such as posterior probability.

As our secondary research question, we examined how color coding and labeling affected learners' processing of the lesson, in other words, what learners did while reading the lesson. To test the effects of color coding and labeling on the processing of the lesson, we used eyetracking. According to the eye-mind hypothesis, the eye fixates (i.e., pauses) on what the mind is processing (Just \& Carpenter, 1980). In this way, eye movements can be used to infer how information is processed (Rayner, 1998). We were specifically interested in how labeling and color coding affected attention to important areas of a text, integration of relevant information in text and tables, and the time spent processing the lesson.

Color coding and labeling are thought to assist learners in selecting important information (Ozcelik et al., 2009; Mayer \& Johnson, 2008). This selection of important information would likely yield an increase in attention to that information (Mayer, 2014). Eyetracking measures can 
yield information about how much a learner attends to a particular section of a lesson. The eyetracking measure of total fixation time is the summed duration of fixations on a particular area and is indicative of attention to that area (Johnson \& Mayer, 2012; Rayner, 1977). Color coding has been previously shown to increase attention to color coded areas of a visual representation (Ozcelik et al., 2009). Labeling has not been found to increase attention as indicated by total fixation time on visual representation as a whole (Johnson \& Mayer, 2012; Mason et al., 2013b). However, these studies (Johnson \& Mayer, 2012; Mason et al., 2013b) did not examine whether labeling increased attention to specific areas of a visual representation. Given that labeling is thought to increase attention to specific areas of a visual representation (Florax \& Ploetzner, 2010), it is likely that total fixation time would be longer if an area of a visual representation is labeled. In addition, the combined use of color coding and labeling could increase attention to specific areas of a visual representation. Both the color contrast and label could signal to learners that a particular area of a visual representation is important, leading to increased attention to that area, relative to color coding alone or labeling alone.

Eyetracking can also be useful for examining how learners integrate information from visual representations and text. Learners may look to and from different representations as they attempt to align and integrate relevant information (Mason, Tornatora, \& Pluchino, 2013c). Previous research findings have indicated that color coding can assist in integrating corresponding information between text and diagrams (Ozcelik et al., 2009). In addition, labeling has been found to increase looks between text and corresponding information in a diagram (Johnson \& Mayer, 2012; Mason et al., 2013b). Therefore, based on previous research (Ozcelik et al., 2009, 2010; Mason et al., 2013b), we expected that both color coding and labeling would increase looks from the text to relevant information in the table and vice versa. 
We were also interested in how color coding and labeling influenced the time spent with the lesson. Given that color coding and labeling add information to the lesson, it is logical that these instructional design techniques could increase the amount of time spent on the lesson (e.g., Johnson \& Mayer, 2012). This increased time with the lesson could explain any observed learning benefits due to instructional design techniques.

If differences as a function of color coding and labeling are found, both in performance and in in how the lessons are processed in terms of integration, attention, and time on task, it is possible that observed differences in performance could be due to the observed differences in processing. To address this issue, we also examined relationships between the processing of the lesson (integration, attention, and time with the lesson) and performance.

We also assessed participants' need for cognition. As described above, findings from previous studies (Klaczynski, 2014; Kokis et al., 2002; Morsanyi et al., 2009) have shown that need for cognition is related to probabilistic reasoning skills. Therefore, we expected that need for cognition would be related to participants' ability to compute posterior probabilities after our training sessions. Despite random assignment, there were pre-existing differences in need for cognition between the labeling and no labeling conditions, so we controlled for the statistical effects of need for cognition in addressing each of these research questions.

\section{Methods}

\section{Participants}

Undergraduate students $(N=103)$ participated for extra credit in a psychology course. Eyetracking data were not recorded for 2 participants due to apparatus malfunction. In addition, 3 participants did not complete all of the necessary measures. Of the remaining 98 participants, $63 \%$ were female and $36 \%$ were male, and their average age was 18.92 years $(S D=1.68$ years; 2 
participants did not report age). Per self-report, 2\% of participants were African American, 5\% were Asian, 3\% were Hispanic or Latino, $86 \%$ were Caucasian, 1\% were Native American, and 3\% were biracial. All participants reported being native speakers of English and all had normal or corrected-to-normal vision.

\section{Materials}

Each participant saw two pages of a website with material adapted from Gigerenzer, Gaissmaier, Kurz-Milcke, Schwartz, and Woloshin (2007). The first page had only text and introduced posterior probability as a means to accurately interpret test results. The second page had text as well as a table with frequency information. There were four versions of the second page of the website, reflecting a 2 (color coding/no color coding) by 2 (labeling/no labeling) design: color coding and labeling, color coding and no labeling, labeling and no color coding, and no color coding or labeling (control). Four of the sentences in the color coding and/or labeling conditions had buttons for participants to click to add color coding and/or labeling (depending on the condition). If a participant was in the control condition, there were no buttons as there was no color coding or labeling to add. See Figure 1 and Figure 2 for examples of the website conditions. 
Understanding health statistics

Breast cancer screening base rates

\begin{tabular}{|l|l|l|l|}
\hline \multicolumn{1}{|l|}{} & Women who test positive & Women who test negative & Sum \\
\hline Breast Cancer & 9 & 1 & 10 \\
\hline No breast cancer & 89 & 901 & 990 \\
\hline Sum & 98 & 902 & 1000 \\
\hline
\end{tabular}

To help explain the answer, follow the statements in relation to the table:

1. The probability that a woman has breast cancer is $1 \%$ (prevalence), that is roughly 10 in 1000

2. If a woman does have breast cancer, the probability that she will test positive is $90 \%$ (true positive rate), that is 9 out of 10

3. If a woman does not have breast cancer, the probability that she will test positive is around $9 \%$ (false positive rate), that is 89 out of 990

4. Therefore, 9 out of 98 women who test positive have breast cancer, that is, roughly 1 in 11 women who test positive actually have breast cancer.

As you can see, if a woman tests positive for breast cancer, it's actually more likely that she doesn't actually have breast cancer than she has breast cancer.

Figure 1. Website without color coding or labeling

\section{Understanding health statistics}

Breast cancer screening base rates

\begin{tabular}{|l|l|l|l|}
\hline \multicolumn{1}{l|}{} & Women who test positive & Women who test negative & Sum \\
\hline Breast Cancer & 9 & 1 & $10 \quad$ prevalence \\
\hline No breast cancer & 89 & 901 & 990 \\
\hline Sum & 98 & 902 & 1000 \\
\hline
\end{tabular}

To help explain the answer, follow the statements in relation to the table:

(сцск) 1. The probability that a woman has breast cancer is $1 \%$ (prevalence), that is roughly 10 in 1000

(CLCK) 2. If a woman does have breast cancer, the probability that she will test positive is $90 \%$ (true positive rate), that is 9 out of 10

(cLCk) 3. If a woman does not have breast cancer, the probability that she will test positive is around $9 \%$ (false positive rate), that is 89 out of 990 (CLCK) 4. Therefore, 9 out of 98 women who test positive have breast cancer, that is, roughly 1 in 11 women who test positive actually have breast cancer.

(CLEAR)

As you can see, if a woman tests positive for breast cancer, it's actually more likely that she doesn't actually have breast cancer than she has breast cancer.

\section{Figure 2. Website with color coding and labeling}

If a participant was in a labeling condition, clicking the button caused a call-out box to appear in the table with an important term next to the cell representing the term. The term in a particular label was used in the sentence next to that button. Only one label appeared at a time. The presentation of only one label at a time after clicking a button was intended to help 
participants understand which cell referred to the term in the sentence. If all labels were visible at the same time, it would not be clear which label corresponded to which sentence. In addition, having only one label appear at a time avoids cluttering the lesson, which would be undesirable (Fisher, Godwin, \& Seltman, 2014; Rosenholtz, Li, Mansfield, \& Jin, 2005; Tufte, 2001).

If a participant was in a color-coding condition, clicking the button caused the sentence in the text and corresponding information in the table to be highlighted in the same color. Because color could be broadly applied to multiple cells, color coding was applied to all cells relevant for a particular sentence. For example, for the sentence explaining what prevalence is, the cell that represents the prevalence received color coding as well as the headings of the row and column of that cell. Also, the cell with the total number of data points was color coded because this information was presented in the text of the sentence.

If a participant was in a condition with both color coding and labeling, clicking a button caused both color coding and labeling to appear. In this way, the specific cell representing a term had a label and color coding appear at the same time. In addition, other corresponding cells and the sentence were color coded.

When a participant clicked a button for the first time during the lesson, color coding and/or labeling appeared (depending on condition). When a participant clicked subsequent buttons, the previously-shown color coding and/or labeling disappeared and new color coding and/or labeling appeared. Thus, only one area of a text and table was color coded or labeled at a time. The text and table were identical across the four conditions. Participants were assigned to conditions using a randomized list of numbers with 25 participants in the no color coding/no labeling condition, 25 participants in the no color coding/labeling condition, 26 participants in the color coding/no labeling condition, and 22 participants in the color coding/labeling condition. 
All participants in conditions with color coding and/or labeling clicked on each button on the website while reading the material.

\section{Measures}

Pretest. The pretest consisted of 2 story problems, each with 4 questions (see Appendix for example). One story problem provided numeric information in a table; one story problem provided numeric information in the text. The first three questions required the prevalence, number of true positives, and number of false positives to be identified. The fourth question required the positive predictive value of a test to be calculated. For each problem, the first three questions were scored by giving 1 point for a correct answer. The fourth question was scored by giving 1 point for the correct numerator and 1 point for the correct denominator (e.g., Berthold, Eysink, \& Renkl, 2009). Incorrect and missing answers were given 0 points. Thus, the highest possible score on the pretest was 10 points (Cronbach's $\alpha=.73$ ).

Comprehension assessment. Learning from multimedia assessments often involves examining retention, comprehension, and transfer of the information in the lesson (Mayer, 1998; Mayer, 2010). Retention is the amount of information that is remembered, comprehension is how well the information was understood, and transfer is whether the information learned in the lesson can be applied to novel situations. To assess retention and comprehension of the lesson, a measure was developed in which participants verified paraphrases and inferences based on the lesson. This measure consisted of 8 sentences, 4 of which were paraphrases (i.e., contained or contradicted information explicitly stated in the lesson) and 4 of which were inferences (i.e., based on or contradicted information in lesson that was not explicitly stated). Participants were asked to indicate whether each sentence was consistent or inconsistent with the information they had just read on the website. Internal consistency for this measure was unacceptable (Cronbach's 
$\alpha=.32$ for the entire measure; Cronbach's $\alpha=.19$ for the paraphrase submeasure, and Cronbach's $\alpha=.25$ for the inference submeasure); therefore, we did not use this measure in analyses and it is not discussed further.

Posttest. The posttest was similar in design to the pretest. It consisted of 4 story problems, each with 4 questions. The posttest was designed to assess transfer of the learned information (Mayer, 1998). Two story problems provided numeric information in a table; two story problems provided numeric information in the text. The posttest was scored in the same manner as the pretest. The highest possible score on the posttest was 20 points (Cronbach's $\alpha=$ $.86)$.

Need for cognition. The Need for Cognition scale consisted of an 18-item scale from Cacioppo, Petty, and Kao (1984). For each item, participants indicated on a Likert scale how characteristic each item was of them. Examples of these items are "The notion of thinking abstractly is appealing to me" and "I would prefer complex to simple problems." Reverse scoring was used on 9 items. The need for cognition score was determined by adding participants' responses to the items (Cronbach's $\alpha=.73$ ).

Eyetracking. The text and tables were divided into areas of interest (AOIs) for eyetracking analyses. Each sentence of the text was a separate AOI, and each cell of the table was a separate AOI. The four sentences that directly corresponded to cells in the table were used to examine looks from the text to the target cells in the table (and vice versa). The four cells to which labels were added in the labeling conditions (i.e., target areas for labeling) were used to examine the effects of labeling on attention to these cells and integration between these cells and relevant sentences. The ten cells to which color coding was added in the color coding conditions 
(i.e., target areas for color coding) were used to examine the effects of color coding on attention to these cells and integration between these cells and relevant sentences.

Fixations less than 50 milliseconds (i.e., microfixations) were deleted prior to all eyetracking data analyses (see similar analyses in Mason, Pluchino, \& Tornatora, \& Ariasi, 2013a). This is because learners need to fixate on information for a minimum of 50 milliseconds to be able to engage in cognitive processing (Rayner, 2009).

\section{Apparatus}

An EyeLink 1000 Desk-Mounted System, manufactured by SR Research Ltd. (Toronto, Ontario, Canada), was used to collect eye movement data. The EyeLink 1000 eye tracker uses an infra-red video camera for monocular tracking, and the video camera was focused on the participants' pupils. The video camera sampled real-time fixations at a $1000 \mathrm{~Hz}$ sampling rate. Head position was stabilized with a chin and forehead rest $70 \mathrm{~cm}$ from the computer monitor displaying the lesson. Pupil diameter was recorded with centroid pupil tracking.

\section{Procedure}

After providing informed consent, participants were given the pretest. Participants were instructed to answer the questions if they knew the answers, but not to guess if they were unsure. After the pretest, the eyetracker was calibrated for each participant. During calibration, participants gazed at a dot that appeared at 5 different points on the screen. This process was repeated until the on-screen gaze position error was less than $.5^{\circ}$ of the visual angle from the target for each eye. The calibration process took between 2-5 minutes. Then participants were instructed to read the information at their own pace and to be sure to understand what they were reading because they would be asked to answer questions about it afterwards. If the participants were in a condition with color coding and/or labeling, they were instructed to click on the 
buttons before each sentence prior to reading that sentence. The participants read the website silently at their own pace. Popup calibration was used to record eye movements as participants viewed the website. Popup calibration is software that allows for eye movements to be recorded while participants view anything on a computer screen. After reading, participants completed a distractor task of 21 simple multiplication and division problems, to prevent rehearsal of the material from the lesson. Then, they were given the posttest with instructions similar to the pretest. Following Kühl, Eitel, Damnik, and Körndle (2014), participants completed the Need for Cognition scale after the posttest (Cacioppo et al., 1984). Finally, they were debriefed and thanked for their participation.

\section{Results}

For all analyses, we set the Type I error rate at $\alpha=.05$.

Prior to analyses testing the effectiveness of labeling and color coding, we examined the distribution of pretest and need for cognition scores across conditions. Table 1 presents descriptive statistics for pretest scores by condition. To examine a priori differences in pretest score by condition, a 2 (color coding) by 2 (labeling) ANOVA was conducted. There were no differences in pretest scores as a function of color coding condition, $F(1,97)=.43, p=.81$. However, despite random assignment, there was an a priori difference in pretest scores as a function of labeling condition, such that participants in the labeling condition had lower pretest scores than did participants in the no labeling condition, $F(1,97)=6.45, p=.01$, Cohen's $d=$ .51 . There was no interaction between the color-coding and labeling conditions, $F(1,97)=.49, p$ $=.49$. Therefore, we partialled out the statistical effects of pretest scores in our analyses. 
Table 1

Descriptive statistics of pretest scores by condition

\begin{tabular}{lccc}
\hline & Color Coding & No Color Coding & Total \\
\hline$M(S E)$ & $M(S E)$ & $M(S E)$ \\
\hline Labeling & $3.95(.59)$ & $3.56(.54)$ & $3.76(.40)$ \\
No Labeling & $5.07(.52)$ & $5.20(.54)$ & $5.14(.37)$ \\
\hline Total & $4.51(.39)$ & $4.38(.38)$ & \\
\hline
\end{tabular}

Table 2 presents descriptive statistics for need for cognition scores by condition. To examine differences in need for cognition score by condition, a 2 (color coding) by 2 (labeling) ANOVA was conducted. Results indicated that there were no differences in need for cognition scores as a function of color-coding condition, $F(1,97)=4.27, p=.04$. However, despite random assignment, participants in the labeling conditions had lower need for cognition scores than did participants in the no labeling conditions, $F(1,97)=1.84, p=.04$, Cohen's $d=.39$. There was no interaction between the color-coding and labeling conditions, $F(1,97)=.48, p=$ .50. Given that need for cognition is a highly stable individual difference variable (Sadowski \& Gulgoz, 1992), it is likely that these differences were a priori and not the result of the labeling condition. Therefore, we also partialled out the statistical effects of need for cognition in our analyses. 
Table 2

Descriptive statistics of need for cognition scores by condition

\begin{tabular}{lccc}
\hline & Color Coding & No Color Coding & Total \\
\hline & $M(S E)$ & $M(S E)$ & $M(S E)$ \\
\hline Labeling & & & \\
No Labeling & $55.52(1.74)$ & $59.00(1.60)$ & $57.26(1.18)$ \\
\hline Total & $60.26(1.54)$ & $60.96(1.60)$ & $60.61(1.11)$ \\
\hline
\end{tabular}

\section{Did color coding and labeling promote learning from the lessons?}

We hypothesized that both labeling and color coding would increase learning. To test this hypothesis, we conducted a 2 (color coding) by 2 (labeling) between subjects ANCOVA with posttest scores as the dependent variable, and pretest scores and need for cognition scores as covariates. Surprisingly, pretest score was not significant as a covariate, $F(1,95)=2.76, p=.10$, $\eta^{2}=.02$. As expected, need for cognition was strongly associated with posttest scores, $F(1,95)=$ $14.30, p<.001, \eta^{2}=.13$. Figure 3 presents adjusted means and standard errors of posttest scores by condition. Participants whose materials included labeling scored higher on posttest than did participants whose materials did not include labeling, $F(1,95)=5.64, p=.02$, Cohen's $\hat{d}=.50$. The effect of color coding on posttest scores was not significant, $F(1,95)=.17, p=.68$, and there was no interaction between color coding and labeling, $F(1,95)=.76, p=.39$. In brief, labeling significantly improved learning, but color coding did not. 


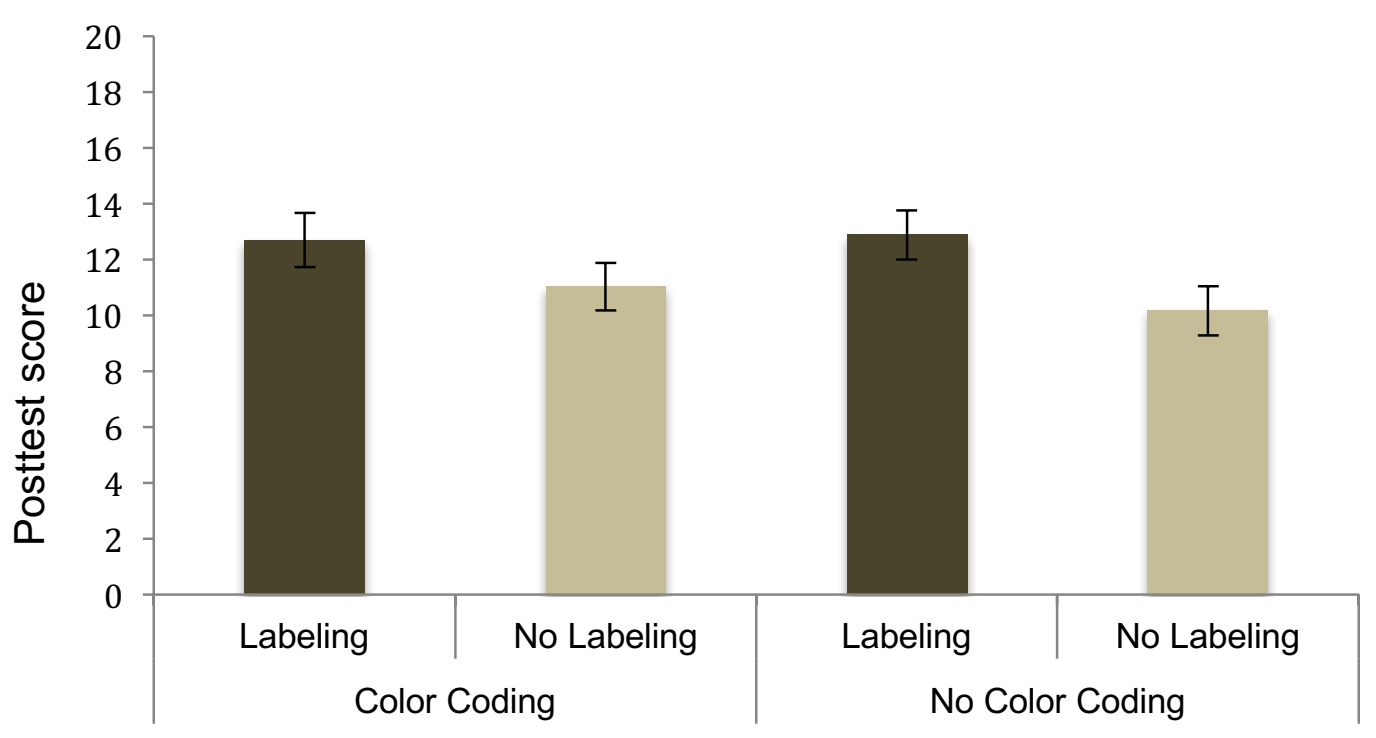

Figure 3. Average posttest score in each condition (means and $+/-1$ standard error bars adjusted for covariates of pretest score and need for cognition score)

\section{Did color coding or labeling increase attention to target areas of the table?}

Because our eyetracking variables provide multiple data points for each participant, we used mixed effects models (e.g., see Snijders \& Bosker, 2012 for more information), implemented using the package lme4 in the R statistical software (Bates, 2010; Bates, Maechler, \& Bolker, 2012). Specifically, we used a mixed effects model with color coding and labeling as fixed factors (both centered at zero), AOI and participant as random factors, and eyetracking variables as the dependent variables. We also included fixed effects for the covariates of need for cognition and pretest score (both z-scored). We report Type III Wald chi-square tests of the parameter estimates against 0. For tests with Poisson distributions, lme4 provides Wald $z$. For tests with Gaussian distributions, lme4 provides Wald $t$. 
To examine how color coding and labeling may have influenced attention to target areas for color coding and labeling, we analyzed total fixation time (summed duration of fixations on an area of interest). To assess the effects of color coding on attention, we examined total fixation time on target areas for color coding (10 cells). We used a mixed model with color coding and labeling as fixed factors, participants and areas of interest as random factors, and total fixation time as a dependent variable. We also included fixed effects for the covariates of need for cognition and pretest score. Total fixation time was square-root transformed to improve normality. Means and standard errors of transformed total fixation times adjusted for pretest scores and need for cognition scores are presented by condition in Figure 4.

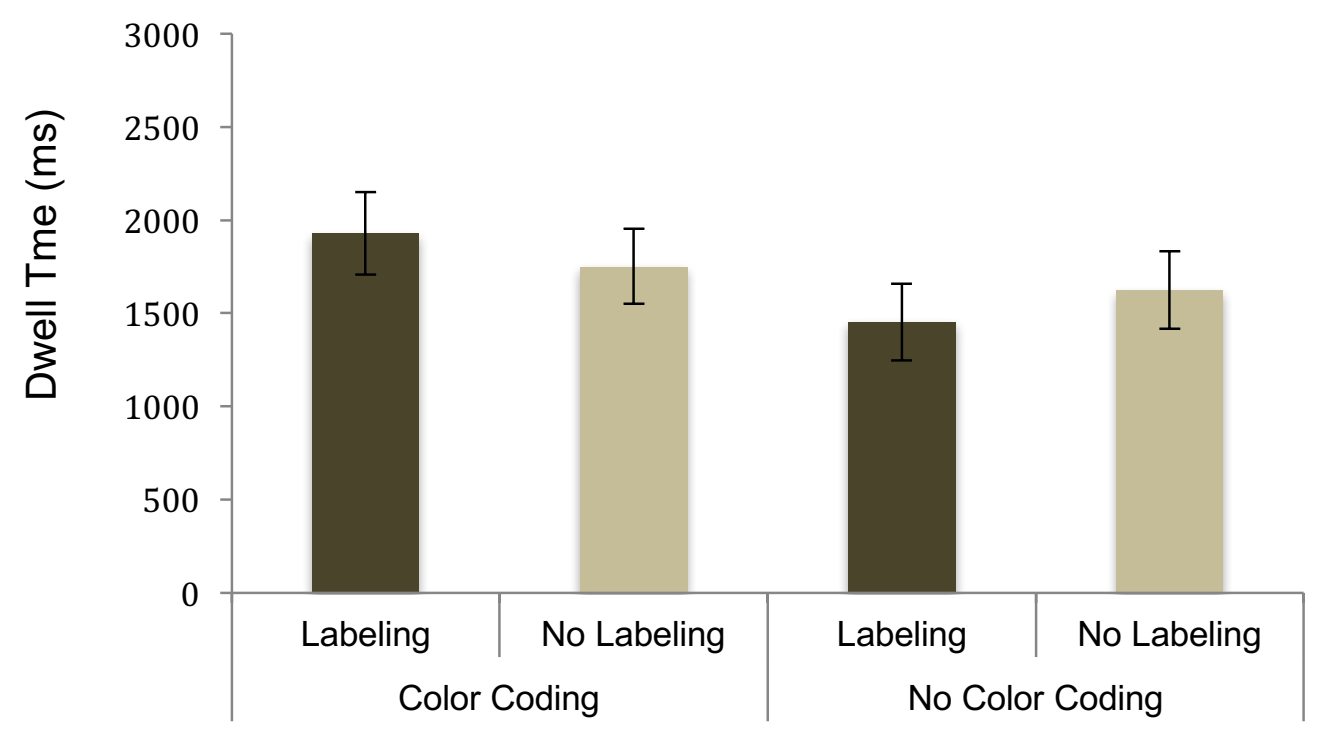

Figure 4. Average dwell time on target areas for color coding in each condition (means and +/- 1 standard error bars adjusted for covariates of pretest score and need for cognition score) 
We had expected that color coding would increase attention to target areas for color coding. However, color coding did not significantly increase total fixation time on target areas for color coding, $b=3.95$, Wald $t=1.52$, Wald $\chi^{2}(1, \mathrm{~N}=98)=2.32, p=.12$. Labeling also did not increase total fixation time on target areas for color coding, $b=-.71$, Wald $t=-.27$, Wald $\chi^{2}(1, \mathrm{~N}=98)=.07, p=.79$. The interaction between color coding and labeling also was not significant, $b=2.54$, Wald $t=.49$, Wald $\chi^{2}(1, \mathrm{~N}=98)=.24, p=.62$. Pretest score was not a significant predictor, $b=-1.65$, Wald $t=-1.24$, Wald $\chi^{2}(1, \mathrm{~N}=98)=3.47, p=.22$, neither was need for cognition, $b=-2.50$, Wald $t=-1.86$, Wald $\chi^{2}(1, \mathrm{~N}=98)=3.47, p=.06$.

To assess the effects of labeling on attention, we examined total fixation time on target areas for labeling ( 4 cells). The same analyses conducted for color coded cells were conducted for labeled cells. We had expected that labeling would increase attention towards target areas for labeling. Recall that target areas for labeling received both color coding and labeling in the color coding and labeling condition. Therefore, we expected that participants in the color coding and labeling condition would demonstrate the most attention towards target areas for labeling. Means and standard errors of transformed total fixation times adjusted for pretest score and need for cognition are presented by condition in Figure 5. As expected, labeling increased total fixation time on target areas for labeling, $b=6.04$, Wald $t=1.99$, Wald $\chi^{2}(1, \mathrm{~N}=98)=3.94, p=.05$. Color coding did not increase total fixation time on target areas for labeling, $b=4.31$, Wald $t=$ 1.45 , Wald $\chi^{2}(1, \mathrm{~N}=98)=2.11, p=.38$. There was no interaction between labeling and color coding, $b=2.66$, Wald $t=.45$, Wald $\chi^{2}(1, \mathrm{~N}=98)=.20, p=.65$. Pretest score was not a significant predictor, $b=-.42$, Wald $t=-.28$, Wald $\chi^{2}(1, \mathrm{~N}=98)=.08, p=.78$, and neither was need for cognition, $b=-2.62$, Wald $t=1.71$, Wald $\chi^{2}(1, \mathrm{~N}=98)=2.93, p=.09$. Taken together, the findings indicate that labeling increased attention to target areas for labeling, but color coding 
did not affect attention to target areas for color coding. Further, there is no evidence that a combination of color coding and labeling enhanced attention to target areas for labeling.

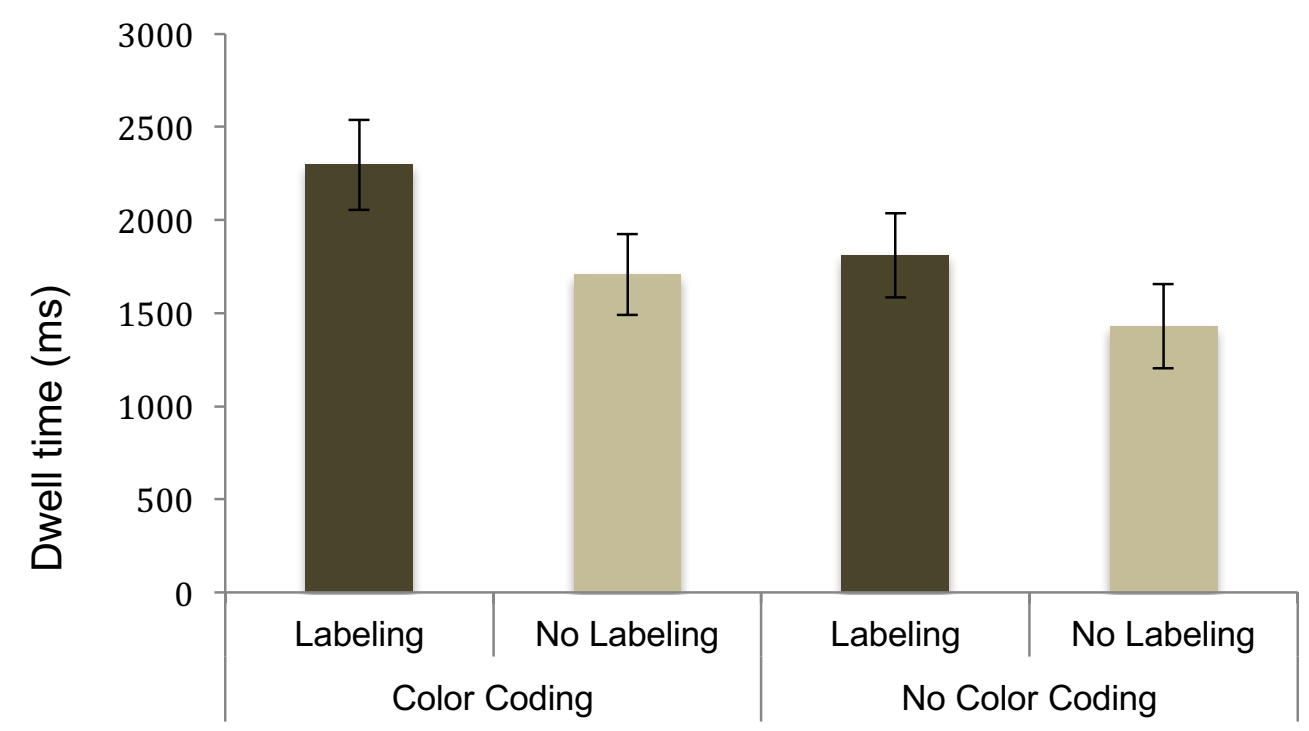

Figure 5. Dwell time for target areas for labeling in each condition (means and +/- 1 standard error bars adjusted for covariates of pretest score and need for cognition score)

Did color coding and labeling influence participants' looks between relevant areas of the text and table?

To better understand how color coding and labeling may have influenced the process of integrating corresponding ideas in the text and table, we analyzed eye movements. To examine potential effects of color coding on integration, we combined two measures: the number of looks from the sentences to relevant target areas for color coding and the number of looks from target areas for color coding to the relevant sentences (see Mason et al., 2013c for similar methodology). We hypothesized that color coding would increase looks between the relevant sentences and the target areas for color coding. 
To test this hypothesis, we conducted a mixed effects model with color coding and labeling as fixed factors, participant and AOI as random factors, pretest score and need for cognition as covariates, and both the number of looks from the sentence to relevant target area for color coding and the number of looks between the target area for color coding to the relevant sentence as the dependent variable (Poisson distribution). Means and standard errors of looks between sentences and relevant target areas for color coding adjusted for pretest score and need for cognition are presented by condition in Figure 6.

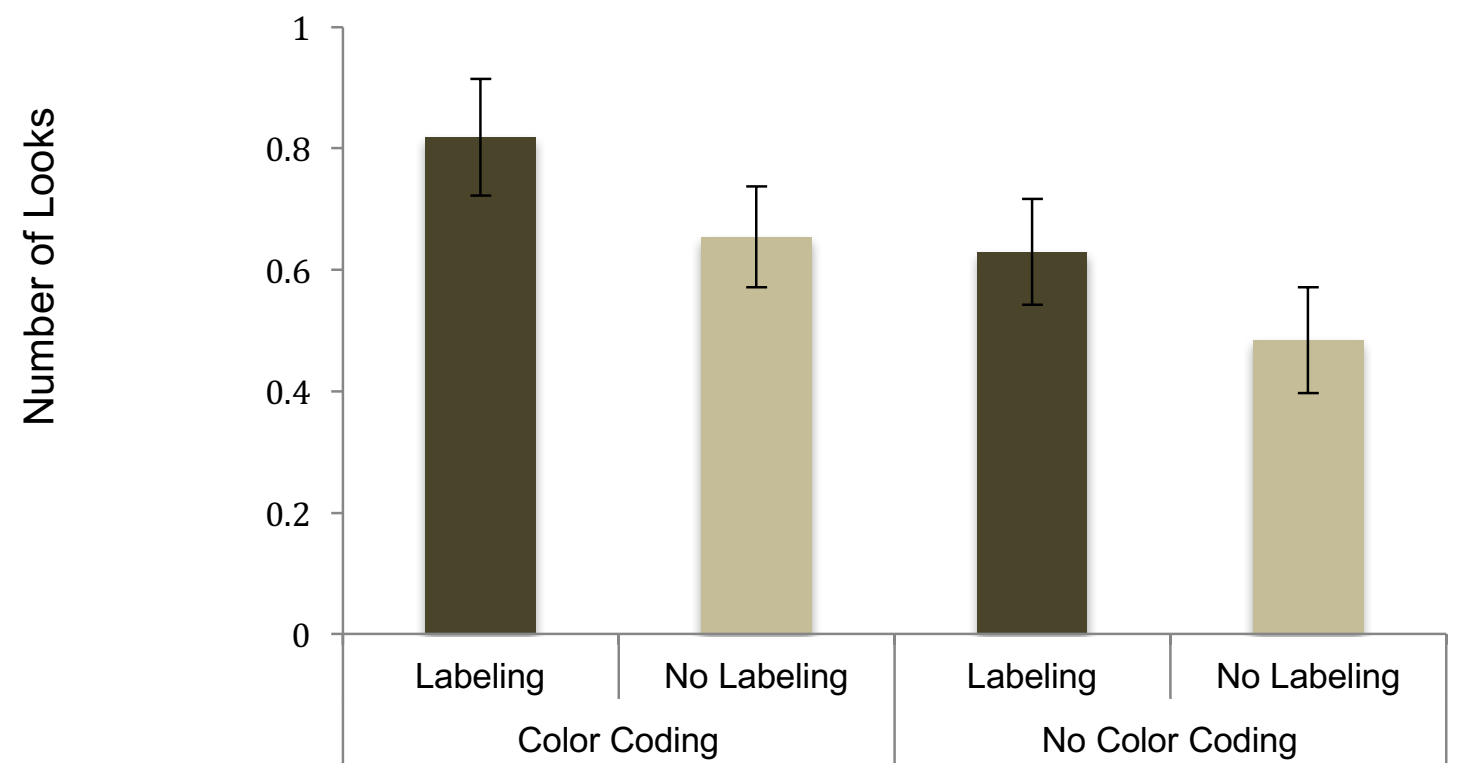

Figure 6. Average looks between sentences and relevant target areas for color coding in each condition (means and +/- 1 standard error bars adjusted for covariates of pretest score and need for cognition score)

Consistent with expectations, color coding increased the number of looks between sentences to relevant target areas for color coding, $b=.30$, Wald $z=1.98$, Wald $\chi^{2}(1, \mathrm{~N}=98)=$ $3.92, p=.05$. Also, labeling had an almost significant effect on increasing the number of looks 
between sentences and relevant target areas for color coding, likely because a subset of these areas were also target areas for labeling, $b=.30$, Wald $z=1.94$, Wald $\chi^{2}(1, \mathrm{~N}=98)=3.76, p=$ .052. There was no interaction between color coding and labeling, $b=-.04$, Wald $z=-.12$, Wald $\chi^{2}(1, \mathrm{~N}=98)=.02, p=.90$. Pretest score was not a significant predictor, $b=-.08$, Wald $z=$ 1.05, Wald $\chi^{2}(1, \mathrm{~N}=98)=1.11, p=.29$, nor was need for cognition, $b=-.14$, Wald $z=-1.79$, Wald $\chi^{2}(1, \mathrm{~N}=98)=3.205, p=.07$.

To examine potential effects of labeling on integration, we combined two measures: the number of looks from the sentences to relevant target areas for labeling and the number of looks from target areas for labeling and the relevant sentence. We hypothesized that labeling would increase looks between the relevant sentences and the target areas for labeling. We also hypothesized that combined use of color coding and labeling in the target areas for labeling would yield benefits beyond labeling alone (recall that target areas for labeling also received color coding in the color coding and labeling condition).

To test these hypotheses, we conducted mixed effects models similar to those conducted for color coding, except the dependent variables were the number of looks between the sentence and the relevant target area for labeling as the dependent variable (Poisson distribution). Means and standard errors of looks between sentences and relevant target areas for labeling in the visual adjusted for pretest score and need for cognition are presented by condition in Figure 7. 
Consistent with expectations, labeling increased the number of looks between relevant sentences and target areas for labeling, $b=.73$, Wald $z=3.80$, Wald $\chi^{2}(1, \mathrm{~N}=98)=14.46, p<$ .001 . There was no effect for color coding, $b=.17$, Wald $z=.91$, Wald $\chi^{2}(1, \mathrm{~N}=98)=.83, p=$ .36. Contrary to expectations, there was no interaction between color coding and labeling, $b=$ .08 , Wald $z=-.22$, Wald $\chi^{2}(1, \mathrm{~N}=98)=.05, p=.82$. Pretest score was not a significant predictor, $b=-.04$, Wald $z=-.44$, Wald $\chi^{2}(1, \mathrm{~N}=98)=.19, p=.66$., nor was need for cognition, $b=-.17$, Wald $z=-1.74$, Wald $\chi^{2}(1, \mathrm{~N}=98)=3.02, p=.08$.

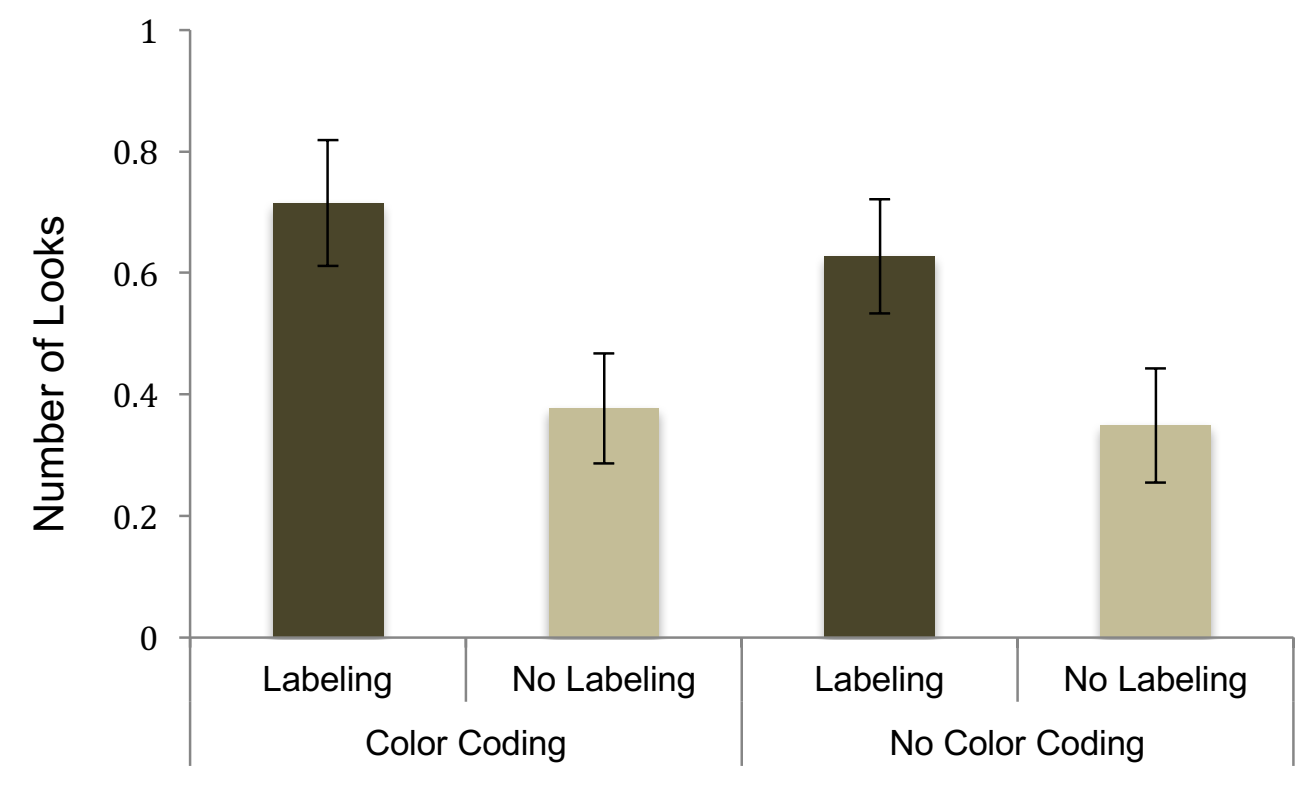

Figure 7. Average looks between sentences and relevant target areas for labeling in each condition (means and +/- 1 standard error bars adjusted for covariates of pretest score and need for cognition score) 


\section{Did color coding or labeling influence time with the lesson?}

To better understand how color coding and labeling may have influenced the amount of cognitive processing of the lesson, we examined time with the lesson. We hypothesized that the information added to the lesson by color coding and labeling may increase time with the lesson. To test this hypothesis, we examined the total sum of fixation durations on the second page of the website (recall that the first page of the website was identical across conditions and the second page varied by condition). The total sum of fixation durations included the duration of all fixations on the second page of the website and indicate the amount of time spent processing that page. The total sum of fixations was square root transformed to improve normality. Nontransformed total sums of fixations adjusted for pretest score and need for cognition are presented by condition in Figure 8.

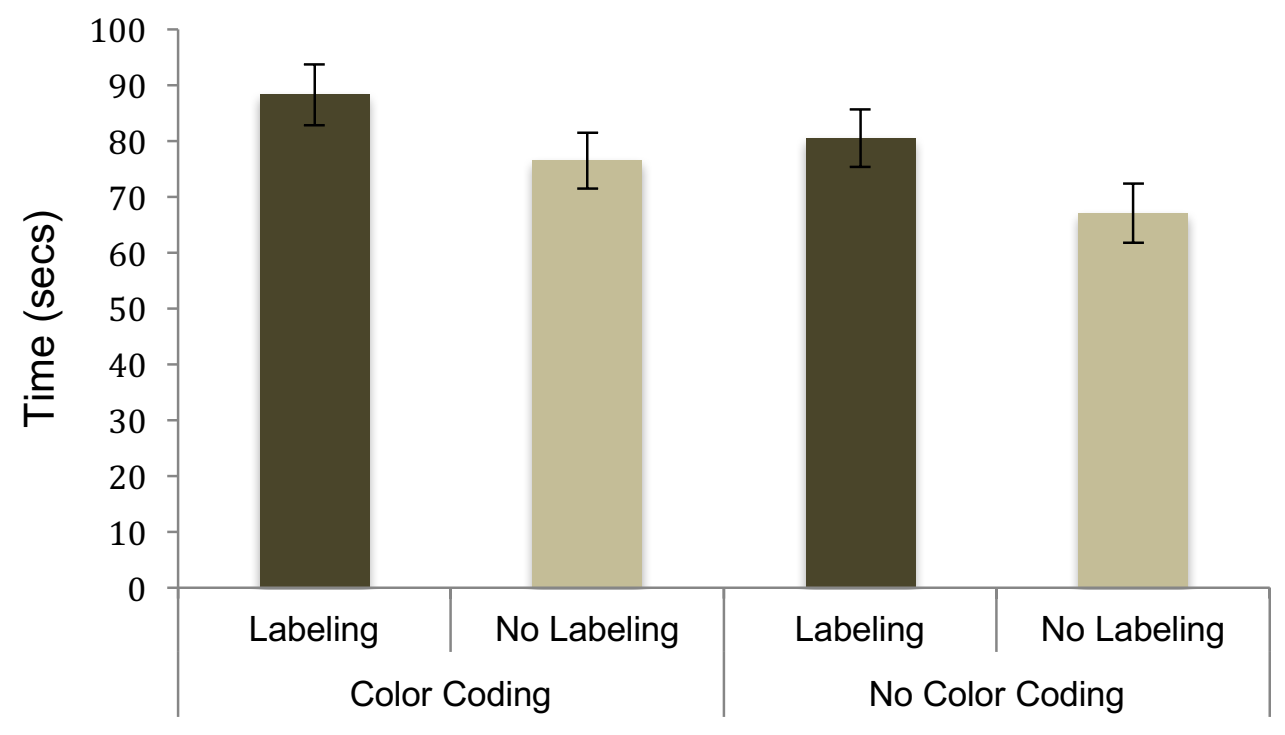

Figure 8. Average time with the lesson in each condition (means and +/- 1 standard error bars adjusted for covariates of pretest score and need for cognition score) 
Because each participant only had one total sum of fixation durations measure, mixed effects modeling was not possible. Instead, a general linear model was used with total sum of fixations as the dependent variable, color coding and labeling as independent variables, and pretest score and need for cognition as covariates. Consistent with hypotheses, labeling increased the total sum of fixation durations, $b=26.31, \chi^{2}(1, \mathrm{~N}=98)=7.84, t=2.8, p=.01$. There was no effect of color coding, $b=12.343, \chi^{2}(1, \mathrm{~N}=98)=1.72, t=2.80, p=.19$. There was no interaction between labeling and color coding, $b=-6.97, \chi^{2}(1, \mathrm{~N}=98)=.14, t=-.38, p=.71$. Pretest score was not a significant predictor, $b=-5.87, \chi^{2}(1, \mathrm{~N}=98)=1.54, t=-1.24, p=.22$, nor was need for cognition, $\mathrm{b}=-2.11, \chi^{2}(1, \mathrm{~N}=98)=.19, t=-.44, p=.66$.

What are the relationships between the processing of the lesson and performance on the lesson?

It is possible that how the lesson was processed in terms of attention, integration, and time with the lesson relates to performance. To examine this possibility, we conducted a series of general linear models with the eyetracking variables in which an effect of labeling was noted as the predictor variable (i.e., fixation duration on target areas for labeling, looks from the text to relevant cells in the table, looks from the labeled cells to relevant sentences, and total sum of fixation duration on the lesson, all z-scored) and posttest score as the dependent variable. To be consistent with previous analyses, need for cognition and pretest were included as covariates. Standardized beta coefficients are reported. There was no effect of fixation duration on target areas for labeling and posttest scores, $b=-.02, \chi^{2}(1, \mathrm{~N}=98)=.27, t=-.52, p=.61$. Pretest was not a significant predictor of posttest scores, $b=.47, \chi^{2}(1, \mathrm{~N}=98)=.97, t=.99, p=.33$, but need for cognition was $b=1.52, \chi^{2}(1, \mathrm{~N}=98)=9.86, t=3.14, p=.002$; For looks between the text to relevant cells in the table, there was no effect on posttest scores, $b=-.05, \chi^{2}(1, \mathrm{~N}=98)=$ 
$.04, t=-.2, p=.84$. Pretest was not a significant predictor of posttest score, $b=.47, \chi^{2}(1, \mathrm{~N}=98)$ $=.1 .01, t=1.01, p=.32$, but need for cognition was, $b=1.57, \chi^{2}(1, \mathrm{~N}=98)=11.00, t=3.32, p$ $=.001$. There was no effect of total fixation time on the lesson on posttest score, $b=.17, \chi^{2}(1, \mathrm{~N}$ $=98)=.14, t=.38, p=.71$. Pretest was not a significant predictor of posttest score, $b=.50, \chi^{2}(1$, $\mathrm{N}=98)=1.14, t=1.07, p=.29$, but need for cognition was, $b=1.60, \chi^{2}(1, \mathrm{~N}=98)=.11 .92, t=$ $3.45, p<.001$. Therefore, it does not appear that the benefits of labeling on learning performance are related to the influence of labeling on these measures of the learning process.

\section{Discussion}

This study examined the effects of color coding and labeling on learning from computerbased written lessons on posterior probability. We asked whether color coding and labeling would increase learning about posterior probability. Based on the multimedia principle and on previous research findings, we expected that both color coding and labeling would promote learning (Florax \& Ploetzner, 2010; Mayer, 2009; Ozcelik et al., 2009, 2010). In addition, we expected that a combination of color coding and labeling might be more beneficial for learning than either color coding or labeling alone, as learners would benefit from two forms of guidance. We found that labeling increased learning, but color coding did not. Further, there was no increased benefit of labeling if there was color coding as well.

\section{Performance}

As expected, labeling benefited learning, which is consistent with findings in the previous literature (Florax \& Ploetzner, 2010; Johnson \& Mayer, 2012; Mason et al., 2013b). Given that the label consists of text, labeling can increase the spatial contiguity of relevant information in visual and verbal representations, allowing learners to focus their cognitive resources on the lesson content (Mayer, 2009). The finding that labeling can enhance learning about posterior 
probabilities is valuable, as posterior probability is a challenging topic for many people (e.g., Gilovich, Griffin, \& Kahneman, 2002).

Based on previous findings (Ozcelik et al., 2009; Kalyuga et al., 1999; Keller et al., 2006), we had anticipated that color coding would have benefited learning. Our findings did not reveal any significant benefits. We suggest four possible reasons for the pattern of findings regarding learning. The first is that learners may need more guidance on how to connect the text and table than was provided by the color coding, especially for a topic in which college students typically have little background knowledge, such as posterior probability (Evans et al., 2000; Morsanyi et al., 2013). Previous findings have indicated that color coding may not adequately guide learners with low levels of background knowledge to make the connections necessary to understand the concepts in a lesson (Patrick, Carter, \& Wiebe, 2005). The second possibility is that the processing of written lessons with visual representations may be driven primarily by text (Hegarty \& Just, 1993). If learners rely on text to understand the lesson, then it follows that labeling, which is comprised of text, may be most effective in guiding the integration of ideas in different representations. The use of text to guide integration and learning would explain why the learners in this study benefited from labeling, but not from color coding.

Our third and fourth reasons for the null effects of color coding relate to the type of visual used and how color coding were applied. Previous work on color coding has used visuals that are dense, detailed depictions of scientific concepts, such as neurotransmitters or DNA strands (Ozcelik et al., 2009; 2010; Patrick et al, 2005). Because dense visuals contain a great deal of information to process, learners may find color coding helpful in identifying which information is important and relevant to the text out of all the details in the visual (Clark \& Lyons, 2010). In contrast, the visual used in this study (a table) is fairly simple and sparse. Although the 
information was complex, learners may have not found the color coding helpful with such a basic visual. It may not have been difficult to determine which information in the table was relevant to the text given that tables are not as detailed as other visuals (see Butcher \& Aleven, 2013, for similar null findings on color coding with a simple visual). A fourth possibility is that we may have implemented color coding in an ineffective way. We color coded full sentences and sets of table cells; this may have posed a large working memory demand on participants attempting to integrate all of the different sources of information. In addition, the broad use of color coding may have inadvertently made it more difficult to determine what information was most relevant to the text. A version in which single words and single cells are color coded might be more effective (and may be more similar to the labeling that we used).

We had also expected that color coding and labeling might yield more benefit for learning than either instructional design technique alone. This is because the use of two different instructional design techniques would provide two forms of guidance on selecting important information and integrating relevant information. If there was no additive benefit of color coding and labeling, a comparison of which technique was more beneficial would be informative in instructional design. We noted that only labeling benefited learning, and there was no evidence of an enhanced benefit with the addition of color coding. Regardless of the reasons for the observed lack of benefits from color coding, our findings indicate that labeling is more effective than color coding in promoting learning from simple visuals.

\section{Learning process}

One of the proposed benefits for instructional design techniques such as color coding and labeling is that they assist learners in selecting important information (Mayer, 2009). If color coding and labeling helped learners select important information, one would expect an increase 
in visual attention as indicated by total fixation duration (i.e., the amount of time spent gazing on an area; Ozcelik et al., 2010). We found that labeling increased visual attention towards the target areas of the visual for labeling; however color coding did not have the same effect. We propose two possible explanations for the effect of labeling, but lack of effect for color coding. One is that labeling also added information to the target areas of the visual. Given that the visual was relatively simple and clear coupled with the finding that color coding did not affect attention, it is possible that labeling increased attention to the target areas because of the addition of information rather than improved selection of information. The second explanation is that color coding was applied more broadly than labeling. It is possible that the broad application of color coding to multiple cells in the table diffused the effect for selection.

We were also interested in the effects of color coding and labeling on guiding the integration of corresponding information in different representations, as indicated by looks between the text and corresponding information in the table (Mason et al., 2013c). Based on previous findings, we expected that both color coding and labeling would increase looks between sentences and corresponding information in the table (Mason et al., 2013b; Ozcelik et al., 2010). Indeed, our findings indicated that both color coding and labeling increased looks between the text and corresponding information in the table. These looks between relevant information in different representations may have enhanced integration of corresponding ideas in different representations in the lesson.

We also examined whether the instructional design techniques influenced how much time learners spent with the lesson. We anticipated that the instructional design techniques would increase time spent with the lesson given that they add information and simple interactivity. Similar to other findings in this study, we found that labeling increased time with the lesson, but 
color coding did not. In this way, it appeared that labeling increased the amount of engagement with the lesson, as indicated by the time spent on the lesson, but color coding did not. However, time with the lesson was not related to learning from the lesson, as discussed next.

The process variables (attention to target areas, integrating of relevant information in representations, and time with the lesson) did not predict learning from the lesson as indicated by the posttest. Therefore, although labeling appeared to affect the processing of the lesson and learning from the lesson, we did not find evidence that the changes we observed in the processing of the lesson explain the benefit of labeling on learning. These findings differ from other research indicating a relationship between how a lesson is processed in terms of eye movements and learning from that lesson (Mason et al., 2013a, 2013b; Scheiter \& Eitel, 2015). The reason for the difference between the current findings and previous findings may be related to how learning was assessed. In the previous findings (Mason et al., 2013a, 2013b; Scheiter \& Eitel, 2015), relationships between eye movements and learning were found for complex, deep learning, such as transferring knowledge to novel situations, but generally not for measures such as recall or factual knowledge. Although the posttest was designed to have students apply the lesson content in novel situations, the information in the lesson directly instructed the students in how to do so. In this way, the posttest may not have been sufficiently challenging to reveal a relationship with eye movements.

\section{Implications}

The present findings support the multimedia principle, which holds that learning from information with multiple representations (e.g., text and tables) is optimized when corresponding information is connected. For this reason, techniques that prompt connections between corresponding information in different representations are expected to be beneficial. In this 
study, labeling was found to improve learning from the lesson. The spatial contiguity of verbal and visual information afforded by labeling may also have guided connections between the verbal information in the label, the numeric information in the table, and the verbal information in the main text, thereby promoting learning (e.g., Florax \& Ploetzner, 2010). However, we did not find a benefit of color coding for learning, which indicates that perhaps this instructional design technique was not effective for promoting learning from this type of content and visual.

There are practical implications for these findings. The use of computer-based lessons and assignments has become commonplace in postsecondary instruction (Porter, Graham, Spring, \& Welch, 2014). As such, the findings from this study have practical implications for the design of lessons and assignments, especially those aimed at enhancing students' understanding of probabilistic information. Indeed, given that people often struggle with understanding probabilities (e.g., Gilovich, Griffin \& Kahneman, 2002; Stanovich \& West, 1998), it is important to develop instructional materials to support this process. Specifically, the findings indicate that allowing users to add labeling through button clicks may be a useful technique to enhance learning. Recall that the lesson design allowed only one label to appear at a time when a button was clicked. This may have enhanced the effectiveness of labeling for two reasons. One reason is that the label for a corresponding sentence appeared when the learner clicked on the button immediately before that sentence. This may have helped the learner realize that the label was likely relevant to that sentence. In addition, the learner did not need to process multiple labels to determine which one was relevant to the currently-read sentence. This simplified the visual search for corresponding information in the text and table.

\section{Limitations and Future Directions}


Of course, some limitations of this study should be considered when interpreting the results. This study did not thoroughly examine background knowledge, which has been previously found to have important interactions with techniques such as color coding (Cook, 2006). The topic in this study, posterior probability, is one with which this population typically has little background knowledge (Morsanyi \& Handley, 2012). Although we did not find positive effects of color coding on learning, such effects might be observed for learners with high levels of background knowledge, who might be better able to use the color coding to make meaningful connections (Patrick et al., 2005). A future color-coding study on a probabilistic reasoning topic in which there is greater variability of background knowledge among participants may be informative. Such a study could further examine possible interactions of color coding and background knowledge when learning about probabilistic reasoning.

In this study, we used materials with text, rather than video lessons with audio narration, as in most studies of the multimedia effect. We chose to study text as a modality because it afforded the opportunity learners to add the instructional design techniques at their own pace. Allowing learners to process the lesson at their own pace was desirable because of its benefits noted in previous research findings (Boucheix \& Guignard, 2005; Evans \& Gibbons, 2007; Mayer \& Chandler, 2001). However, online and flipped classrooms (i.e., classes in which students watch videos of materials and spend classtime on project work) are becoming increasingly common and these courses typically rely on videos to present course material (Gray, 2014; O'Flaherty \& Phillips, 2015). Previous work on the use of labels in video lessons with visual representations of science concepts has also indicated a benefit for labels (Mayer \& Johnson, 2008). A potentially informative area for future research would be to examine methods 
of making the use of labeling in video lessons interactive. Findings from such research could inform instructional design practices in video lessons.

\section{Conclusion}

Learning about posterior probabilities is particularly challenging, because learners have to integrate several pieces of information (e.g., Gilovich et al., 2002). Although tables and diagrams have been found to be beneficial in instruction on calculating posterior probability (Sedlmeier \& Gigerenzer, 2001), such benefits can only be realized if learners are able to effectively connect the information presented in tables to the explanations in the text. The findings from this study demonstrate that labeling can enhance the integration of corresponding ideas in multiple representations and foster learning. These findings support the multimedia principle in that learning was enhanced through connections between corresponding information in different representations (Mayer, 2009). Moreover, this study also demonstrates the utility of eyetracking for understanding the processes involved in learning. More generally, these findings contribute to a deeper understanding of how students connect ideas across representations, and how external supports, such as labels, can foster their making these connections. Such knowledge can be used to guide the design of instructional materials to support student learning, both in traditional lessons and in computer-based ones. 


\section{References}

Alibali, M. W., Nathan, M. J., Wolfgram, M. S., Church, R. B., Johnson, C. V., Jacobs, S. A., \& Knuth, E. J. (2014). How teachers link ideas in mathematics instruction using speech and gesture: A corpus analysis. Cognition and Instruction, 32(1), 65-100. doi: $10.1080 / 07370008.2013 .858161$

Bates, D. M. (2010). lme4: Mixed-effects modeling with R. URL http://lme4. r-forge. r-project. org/book.

Bates, D., Maechler, M., \& Bolker, B. (2012). lme4: Linear mixed-effects models using S4 classes.

Berthold, K., Eysink, T. H., \& Renkl, A. (2009). Assisting self-explanation prompts are more effective than open prompts when learning with multiple representations. Instructional Science, 37(4), 345-363. doi: 10.1007/s11251-008-9051-z

Boucheix, J. M., \& Guignard, H. (2005). What animated illustrations conditions can improve technical document comprehension in young students? Format, signaling and control of the presentation. European Journal of Psychology of Education, 20(4), 369-388. doi: 10.1007/BF03173563

Boucheix, J. M., \& Lowe, R. K. (2010). An eye tracking comparison of external pointing cues and internal continuous cues in learning with complex animations. Learning and instruction, 20(2), 123-135. doi: 10.1016/j.learninstruc.2009.02.015

Butcher, K. R., \& Aleven, V. (2013). Using student interactions to foster rule-diagram mapping during problem solving in an intelligent tutoring system. Journal of Educational Psychology, 105(4), 988. doi: 10.1037/a0031756 
Cacioppo, J. T., \& Petty, R. E. (1982). The need for cognition. Journal of Personality and Social Psychology, 42(1), 116-131. doi:10.1037/0022-3514.42.1.116

Cacioppo, J. T., Petty, R. E., Feinstein, J. A., \& Jarvis, W. B. G. (1996). Dispositional differences in cognitive motivation: The life and times of individuals varying in need for cognition. Psychological Bulletin, 119(2), 197. doi: 10.1037/0033-2909.119.2.197

Cacioppo, J. T., Petty, R. E., \& Feng Kao, C. (1984). The efficient assessment of need for cognition. Journal of Personality Assessment, 48(3), 306-307. doi: 10.1207/s15327752jpa4803_13

Catrambone, R. (1994). The effects of labels in example on problem solving transfer. In Proceedings of the sixteenth annual conference of the Cognitive Science Society (pp. 159164).

Catrambone, R. (1996). Generalizing solution procedures learned from examples. Journal of Experimental Psychology: Learning, Memory, and Cognition, 22(4), 1020. doi: $10.1037 / 0278-7393.22 .4 .1020$

Chandler, P., \& Sweller, J. (1991). Cognitive load theory and the format of instruction. Cognition and instruction, 8(4), 293-332. doi: 10.1207/s1532690xci0804_2

Chandler, P., \& Sweller, J. (1992). The split-attention effect as a factor in the design of instruction. British Journal of Educational Psychology, 62(2), 233-246. doi: 10.1111/j.2044-8279.1992.tb01017.x

Clark, R. C., \& Lyons, C. (2010). Graphics for learning: Proven guidelines for planning, designing, and evaluating visuals in training materials ( $2^{\text {nd }}$ ed.). Washington D.C.: Pfeiffer \& Co. 
Cook, M. P. (2006). Visual representations in science education: The influence of prior knowledge and cognitive load theory on instructional design principles. Science Education, 90(6), 1073-1091. doi: 10.1002/sce.20164

de Koning, B. B., Tabbers, H. K., Rikers, R. M., \& Paas, F. (2009). Towards a framework for attention cueing in instructional animations: Guidelines for research and design. Educational Psychology Review, 21(2), 113-140. doi: 10.1007/s10648-009-90987

de Koning, B. B., Tabbers, H. K., Rikers, R. M., \& Paas, F. (2010). Attention guidance in learning from a complex animation: Seeing is understanding?.Learning and Instruction, 20(2), 111-122. doi: 10.1016/j.learninstruc.2009.02.010

Evans, C., \& Gibbons, N. J. (2007). The interactivity effect in multimedia learning. Computers \& Education, 49(4), 1147-1160. doi: doi:10.1016/j.compedu.2006.01.008

Evans, J. S. B., Handley, S. J., Perham, N., Over, D. E., \& Thompson, V. A. (2000). Frequency versus probability formats in statistical word problems.Cognition, 77(3), 197-213. doi: 10.1016/S0010-0277(00)00098-6

Fisher, A. V., Godwin, K. E., \& Seltman, H. (2014). Visual environment, attention allocation, and learning in young children when too much of a good thing may be bad. Psychological Science, 25(7), 1362-1370. doi: 10.1177/0956797614533801

Florax, M., \& Ploetzner, R. (2010). What contributes to the split-attention effect? The role of text segmentation, picture labelling, and spatial proximity. Learning and Instruction, 20(3), 216-224. doi: 10.1016/j.learninstruc.2009.02.021 
Garfield, J. B., \& Ben-Zvi, D. (2008). Developing students'statistical reasoning: Connecting Research and Teaching Practice. The Netherlands: Springer.

Gigerenzer, G., Gaissmaier, W., Kurz-Milcke, E., Schwartz, L. M., \& Woloshin, S. (2007). Helping doctors and patients make sense of health statistics. Psychological Science in the Public Interest, 8(2), 53-96. doi: 10.1111/j.1539-6053.2008.00033.x

Gilovich, T., Griffin D., \& Kahneman, D. (Eds.). (2002). Heuristics and biases: The psychology of intuitive judgment. Cambridge, UK: Cambridge University Press.

Gray, D. (2014). Barriers to online postsecondary education crumble: Enrollment in traditional face-to-face courses declines as enrollment in online courses increases. Contemporary Issues in Education Research (CIER), 6(3), 345-348. Retrieved from http://www.cluteinstitute.com/ojs/index.php/CIER/article/view/8537

Haugtvedt, C. P., Petty, R. E., \& Cacioppo, J. T. (1992). Need for cognition and advertising: Understanding the role of personality variables in consumer behavior. Journal of Consumer Psychology, 1(3), 239-260. doi: 10.1016/S1057-7408(08)80038-1

Hegarty, M., \& Just, M. A. (1993). Constructing mental models of machines from text and diagrams. Journal of memory and language, 32(6), 717-742. doi: 10.1006/jmla.1993.1036

Heijltjes, A., Van Gog, T., Leppink, J., \& Paas, F. (2014). Improving critical thinking: Effects of dispositions and instructions on economics students' reasoning skills. Learning and Instruction, 29, 31-42. doi: 10.1016/j.learninstruc.2013.07.003

Hoffrage, U., Kurzenhauser, S., \& Gigerenzer, G. (2005). Understanding the results of medical tests: Why the representation of statistical information matters. In R. Bibace, J. D. Laird, K. L. Noller, \& J. Valsiner (Eds.), Science and medicine in dialogue: thinking through 
particulars and universals (pp. 83-98). Westport: Praeger Publishers/Greenwood Publishing Group.

Holsanova, J., Holmberg, N., \& Holmqvist, K. (2009). Reading information graphics: The role of spatial contiguity and dual attentional guidance. Applied Cognitive Psychology, 23(9), 1215-1226. doi: 10.1002/acp. 1525

Jamet, E., Gavota, M., \& Quaireau, C. (2008). Attention guiding in multimedia learning. Learning and instruction, 18(2), 135-145. doi: 10.1016/j.learninstruc.2007.01.011

Jarvis, W. B. G., \& Petty, R. E. (1996). The need to evaluate. Journal of Personality and Social Psychology, 70(1), 172. doi: 10.1037/0022-3514.70.1.172

Johnson, C. I., \& Mayer, R. E. (2012). An eye movement analysis of the spatial contiguity effect in multimedia learning. Journal of Experimental Psychology: Applied, 18(2), 178. doi: $10.1037 / \mathrm{a} 0026923$

Just, M. A., \& Carpenter, P. A. (1980). A theory of reading: from eye fixations to comprehension. Psychological Review, 87(4), 329. doi: 10.1037/0033-295X.87.4.329

Kahneman, D., \& Tversky, A. (1973). On the psychology of prediction.Psychological review, 80(4), 237. doi: 10.1037/h0034747

Kalyuga, S., Chandler, P., \& Sweller, J. (1999). Managing split-attention and redundancy in multimedia instruction. Applied Cognitive Psychology, 13(4), 351-371.

Keller, T., Gerjets, P., Scheiter, K., \& Garsoffky, B. (2006). Information visualizations for knowledge acquisition: The impact of dimensionality and color coding. Computers in Human Behavior, 22(1), 43-65. doi: 10.1016/j.chb.2005.01.006 
Klaczynski, P. A. (2014). Heuristics and biases: interactions among numeracy, ability, and reflectiveness predict normative responding. Frontiers in Psychology, 5, 665. doi: 10.3389/fpsyg.2014.00665

Kokis, J. V., Macpherson, R., Toplak, M. E., West, R. F., \& Stanovich, K. E. (2002). Heuristic and analytic processing: Age trends and associations with cognitive ability and cognitive styles. Journal of Experimental Child Psychology, 83(1), 26-52. doi: 0.1016/S00220965(02)00121-2

Kühl, T., Eitel, A., Damnik, G., \& Körndle, H. (2014). The impact of disfluency, pacing, and students' need for cognition on learning with multimedia. Computers in Human Behavior, 35, 189-198. doi: 10.1016/j.chb.2014.03.004

Kurzenhäuser, S., \& Hertwig, R. (2006). How to foster citizens' statistical reasoning: implications for genetic counseling. Public Health Genomics, 9(3), 197-203.

Kurzenhäuser, S., \& Hoffrage, U. (2002). Teaching Bayesian reasoning: An evaluation of a classroom tutorial for medical students. Medical Teacher, 24(5), 516-521. doi: $10.1080 / 0142159021000012540$

Low, R., \& Sweller, J. (2005). The modality principle in multimedia learning. In R. Mayer (Ed.), Cambridge handbook of multimedia learning (pp. 147-158). New York: Cambridge University Press.

Mason, L., Pluchino, P., Tornatora, M. C., \& Ariasi, N. (2013a). An eye-tracking study of learning from science text with concrete and abstract illustrations. The Journal of Experimental Education, 81(3), 356-384. doi: 10.1080/00220973.2012.727885 
Mason, L., Pluchino, P., \& Tornatora, M. C. (2013b). Effects of picture labeling on science text processing and learning: Evidence from eye movements. Reading Research Quarterly, 48(2), 199-214.

Mason, L., Tornatora, M. C., \& Pluchino, P. (2013c). Do fourth graders integrate text and picture in processing and learning from an illustrated science text? Evidence from eye-movement patterns. Computers \& Education, 60(1), 95-109. doi: 10.1016/j.compedu.2012.07.011

Mayer, R. E. (1996). Learning strategies for making sense out of expository text: The SOI model for guiding three cognitive processes in knowledge construction. Educational Psychology Review, 8(4), 357-371. doi: 10.1007/BF01463939

Mayer, R. E. (1998). Cognitive, metacognitive, and motivational aspects of problem solving. Instructional science, 26(1-2), 49-63. doi: 10.1023/A:1003088013286

Mayer, R. E. (1999). Designing instruction for constructivist learning. In C.M. Reigeluth (Eds.) Instructional-design theories and models: A new paradigm of instructional theory, (Vol. 2, pp. 141-159). Mahwah, NJ: Lawrence Erlbaum Associates.

Mayer, R. E. (2002). Multimedia learning. Psychology of Learning and Motivation, 41, 85-139. doi: 10.1016/S0079-7421(02)80005-6

Mayer, R. E. (2003). The promise of multimedia learning: using the same instructional design methods across different media. Learning and Instruction,13(2), 125-139. doi: 10.1016/S0959-4752(02)00016-6

Mayer, R. E. (2005). Cognitive theory of multimedia learning. The Cambridge handbook of Multimedia Learning, 31-48.

Mayer, R.E. (2009). Multimedia learning, Second Edition. New York, NY: Cambridge University Press. 
Mayer, R. E. (2014). Cognitive theory of multimedia learning. In R. E. Mayer (Ed.), The Cambridge handbook of multimedia learning (2nd ed., pp. 43-71). New York: Cambridge University Press.

Mayer, R. E., \& Chandler, P. (2001). When learning is just a click away: Does simple user interaction foster deeper understanding of multimedia messages? Journal of Educational psychology, 93(2), 390. doi: 10.1037/0022-0663.93.2.390

Mayer, R. E., \& Johnson, C. I. (2008). Revising the redundancy principle in multimedia learning. Journal of Educational Psychology, 100(2), 380. doi: 10.1037/00220663.100 .2 .380

Moreno, R., \& Mayer, R. E. (1999). Cognitive principles of multimedia learning: The role of modality and contiguity. Journal of Educational Psychology, 91(2), 358. doi: $10.1037 / 0022-0663.91 .2 .358$

Morsanyi, K., \& Handley, S. (2012). Does thinking make you biased? The case of the engineers and lawyer problem. In N. Miyake, D. Peebles, R.P. Cooper (Eds.) Proceedings of the 34th Annual Conference of the Cognitive Science Society (pp. 2049-2054) Austin, TX: Cognitive Science Society.

Morsanyi, K., Handley, S.J. \& Serpell, S. (2013). Making heads or tails of probability. An experiment with random generators. British Journal of Educational Psychology, 83, 379395. doi: $10.1111 / \mathrm{j} .2044-8279.2012 .02067 . \mathrm{x}$

Morsanyi, K., Primi, C., Chiesi, F., \& Handley, S. (2009). The effects and side-effects of statistics education: Psychology students'(mis-) conceptions of probability. Contemporary Educational Psychology, 34(3), 210-220. doi: 10.1016/j.cedpsych.2009.05.001 
Mousavi, S. Y., Low, R., \& Sweller, J. (1995). Reducing cognitive load by mixing auditory and visual presentation modes. Journal of Educational Psychology,87(2), 319. doi: $10.1037 / 0022-0663.87 .2 .319$

Najjar, L. J. (1998). Principles of educational multimedia user interface design. Human Factors: The Journal of the Human Factors and Ergonomics Society,40(2), 311-323. doi: $10.1518 / 001872098779480505$

Nathan, M. J., \& Alibali, M. W. (2011). How gesture use enables intersubjectivity in the classroom. In G. Stam \& M. Ishino (Eds.), Integrating gestures: The interdisciplinary nature of gesture (pp. 257-266). Amsterdam: John Benjamins.

O'Byrne, P. J., Patry, A., \& Carnegie, J. A. (2008). The development of interactive online learning tools for the study of anatomy. Medical Teacher, 30(8), 260-271. doi: $10.1080 / 01421590802232818$

O'Flaherty, J., \& Phillips, C. (2015). The use of flipped classrooms in higher education: A scoping review. The Internet and Higher Education, 25, 85-95. doi: 10.1016/i.iheduc.2015.02.002

Ozcelik, E., Arslan-Ari, I., \& Cagiltay, K. (2010). Why does signaling enhance multimedia learning? Evidence from eye movements. Computers in Human Behavior, 26(1), 110117. doi: $10.1016 /$ j.chb.2009.09.001

Ozcelik, E., Karakus, T., Kursun, E., \& Cagiltay, K. (2009). An eye-tracking study of how color coding affects multimedia learning. Computers \& Education, 53(2), 445-453. doi:10.1016/j.compedu.2009.03.002 
Patrick, M. D., Carter, G., \& Wiebe, E. N. (2005). Visual representations of DNA replication: Middle grades students' perceptions and interpretations. Journal of Science Education and Technology, 14(3), 353-365. doi: 10.1007/s10956-005-7200-6

Porter, W. W., Graham, C. R., Spring, K. A., \& Welch, K. R. (2014). Blended learning in higher education: Institutional adoption and implementation. Computers \& Education, 75, 185 195.

Rayner, K. (1977). Visual attention in reading: Eye movements reflect cognitive processes. Memory \& Cognition, 5(4), 443-448. doi: 10.3758/BF03197383

Rayner, K. (1998). Eye movements in reading and information processing: 20 years of research. Psychological Bulletin, 124(3), 372. doi: 10.1037/0033-2909.124.3.372

Rayner, K. (2009). Eye movements and attention in reading, scene perception, and visual search. Quarterly Journal of Experimental Psychology, 62(8), 1457-1506. doi:10.1080/17470210902816461

Rosenholtz, R., Y. Li, J. Mansfield, Z. Jin. 2005. Feature congestion: A measure of display clutter. Proc. SIGCHI Conf. Human Factors Comput. Systems. ACM Press, New York, 761-767.

Sadowski, C.J., \& Gulgoz, S. (1992). Internal consistency and test-retest reliability of the Need for Cognition scale. Perceptual and Motor Skills, 74, 610. doi: 10.2466/pms.1992.74.2.610

Schnotz, W. (2002). Commentary: Towards an integrated view of learning from text and visual displays. Educational Psychology Review, 14(1), 101-120. doi:

10.1023/A:1013136727916 
Schnotz, W. \& Lowe, R.K. (2008). A unified view of learning from animated and static graphics. In R.K. Lowe \& W. Schnotz (Eds.), Learning with animation: Research implications for design (pp. 304-356). New York: Cambridge University Press.

Scheiter, K., \& Eitel, A. (2015). Signals foster multimedia learning by supporting integration of highlighted text and diagram elements. Learning and Instruction,36, 11-26. doi: 10.1016/j.learninstruc.2014.11.002

Sedlmeier, P., \& Gigerenzer, G. (2001). Teaching Bayesian reasoning in less than two hours. Journal of Experimental Psychology: General, 130(3), 380. doi: 10.1037/00963445.130.3.380

Seufert, T. (2003). Supporting coherence formation in learning from multiple representations. Learning and Instruction, 13(2), 227-237. doi: 10.1016/S09594752(02)00022-1Smith, S. M., \& Levin, I. P. (1996). Need for cognition and choice framing effects. Journal of Behavioral Decision Making, 9(4), 283-290. doi: 10.1002/(SICI)1099-0771

Snijders, T. \& Bosker, R. (2012), Multilevel Analysis: An Introduction to Basic and Applied Multilevel Analysis, 2nd edition. London: Sage.

Stanovich, K. E., \& West, R. F. (1998). Who uses base rates and P (D/ H)? An analysis of individual differences. Memory \& Cognition, 26(1), 161-179. doi: 10.3758/BF03211379

Steckelberg, A., Balgenorth, A., Berger, J., \& Mühlhauser, I. (2004). Explaining computation of predictive values: $2 \times 2$ table versus frequency tree. A randomized controlled trial [ISRCTN74278823]. BMC medical education, 4(1), 13. doi: 10.1186/1472-6920-4-13 
Tabbers, H., Martens, R., \& van Merrienboer, J. J. G. (2004). Multimedia instructions and cognitive load theory: Effects of modality and cueing. British Journal of Educational Psychology, 74, 71-81.

Tufte, E. (2001). The visual display of quantitative information. Cheshire, CT: Graphics.

West, R. F., Toplak, M. E., \& Stanovich, K. E. (2008). Heuristics and biases as measures of critical thinking: Associations with cognitive ability and thinking dispositions. Journal of Educational Psychology, 100(4), 930. doi: 10.1037/a0012842 


\section{Appendix}

Problem from pretest

Answer the questions as best you can. If you don't know an answer, please don't guess! Just leave it blank and move onto the next question. Give proportion answers as a fraction.

\section{Problem 1:}

Imagine you are an obstetrician. One of your pregnant patients gets the serum test to screen her fetus for Down syndrome. The test is a very good one, but not perfect. Based on your clinic records from 10,000 previous patients, answer the questions below.

\begin{tabular}{|l|l|l|l|}
\hline & $\begin{array}{l}\text { Serum test indicates } \\
\text { Down syndrome }\end{array}$ & $\begin{array}{l}\text { Serum test does not } \\
\text { indicate Down } \\
\text { syndrome }\end{array}$ & Sum \\
\hline $\begin{array}{l}\text { With Down } \\
\text { syndrome }\end{array}$ & 90 & 10 & 100 \\
\hline $\begin{array}{l}\text { Without Down } \\
\text { syndrome }\end{array}$ & 99 & 9,801 & 9,900 \\
\hline Sum & 189 & 9,811 & 10,000 \\
\hline
\end{tabular}

What is the prevalence of Down syndrome?

What is the number of true positives for Down syndrome?

What is the number of false positives for Down syndrome?

What is the proportion of fetuses with serum tests indicating Down syndrome who actually have Down syndrome? 